\title{
Electronic brachytherapy for superficial and nodular basal cell carcinoma: a report of two prospective pilot trials using different doses
}

\author{
Rosa Ballester-Sánchez, MD!, Olga Pons-Llanas, MD², Cristian Candela-Juan, MSc³, Francisco Javier Celada-Álvarez, MD² \\ Christopher A. Barker, MD4, Alejandro Tormo-Micó, MD², Jose Pérez-Calatayud, PhD 3., , Rafael Botella-Estrada, MD, PhDl \\ 'Dermatology Department, ${ }^{2}$ Radiation Oncology Department, ${ }^{3}$ Radiotherapy Physics Section, Radiation Oncology Department, \\ La Fe University and Polytechnic Hospital, Valencia, Spain, ${ }^{4}$ Department of Radiation Oncology, Memorial Sloan Kettering Cancer Center, \\ New York, USA, ${ }^{5}$ Radiation Oncology Department, Clinica Benidorm, Alicante, Spain
}

\begin{abstract}
Purpose: Basal cell carcinoma (BCC) is a very common cancer in the Caucasian population. Treatment aims to eradicate the tumor with the lowest possible functional and aesthetic impact. Electronic brachytherapy (EBT) is a treatment technique currently emerging. This study aims to show the outcomes of two consecutive prospective pilot clinical trials using different radiation doses of EBT with Esteya ${ }^{\circledR}$ EB system for the treatment of superficial and nodular basal cell carcinoma.

Material and methods: Two prospective, single-center, non-randomized, pilot studies were conducted. Twenty patients were treated in each study with different doses. The first group (1) was treated with 36.6 Gy in 6 fractions of $6.1 \mathrm{~Gy}$, and the second group (2) with $42 \mathrm{~Gy}$ in 6 fractions of $7 \mathrm{~Gy}$. Cure rate, acute toxicity, and late toxicity related to cosmesis were analyzed in the two treatment groups.

Results: In group 1, a complete response in $90 \%$ of cases was observed at the first year of follow-up, whereas in group 2, the complete response was $95 \%$. The differences with reference to acute toxicity and the cosmetic results between the two treatment groups were not statistically significant.

Conclusions: Our initial experience with Esteya ${ }^{\circledR}$ EB system to treat superficial and nodular BCC shows that a dose of 36.6 Gy and 42 Gy delivered in 6 fraction of 7 Gy achieves a 90\% and 95\% clinical cure rate at 1 year, respectively. Both groups had a tolerable toxicity and a very good cosmesis. The role of EBT in the treatment of BCC is still to be defined. It will probably become an established option for selected patients in the near future.
\end{abstract}

J Contemp Brachytherapy 2016; 8, 1: 48-55 DOI: $10.5114 / j \mathrm{cb} .2016 .57531$

Key words: basal cell carcinoma, electronic brachytherapy, radiation therapy, skin cancer.

\section{Purpose}

Basal cell carcinoma (BCC) is the most common cancer in the Caucasian population with an increasing incidence in recent years [1]. It is a malignant epidermal tumor with a slow growth rate, limited local invasion, and a very low metastatic potential. Basal cell carcinoma is related to chronic exposure to ultraviolet radiation and therefore occurs most commonly on the face. This can have a psychological impact on the patient in terms of both the disease and the possible sequelae of treatment. Left untreated, local invasion results (in very advanced cases) in destruction of soft tissues involving muscle, bone, nerves, or sensory organs, such as the eyes. Further complications that may occur include ulceration, bleeding, infection, and pain. All these aspects contribute to the morbidity of the disease and the consequent impact on the healthcare system. The treatment goal for BCC is eradicate the tumor with the lowest possible functional and aesthetic impact and avoid relapses.

Treatment options include surgery, radiation therapy (RT), photodynamic therapy, topical medications, and systemic medical therapy. Although surgery is the first choice of treatment, RT is indicated in selected cases when surgery is not an option due either to the patient (when surgery presents a high risk) or for procedural (cosmetic or functional) reasons [2]. The radiotherapeutic options, which have been used include superficial X-rays, electron beam, and low or high-dose-rate brachytherapy. Electronic brachytherapy (EBT) is a new technique, which is currently emerging. It delivers low-energy radiation at a high-dose-rate through an applicator placed on the skin.
Address for correspondence: Rosa Ballester Sánchez, MD, Dermatology Department, La Fe University and Polytechnic Hospital, Valencia, Spain, Bulevar sur s/n, 46026 Valencia, Spain, phone: +34 961244186, +34 676076017, $\approx$ e-mail: roseta999@hotmail.com
Received: 29.09 .2015

Accepted: 18.12 .2015

Published: 26.02 .2016 
As EBT uses an X-ray source rather than radioactive isotopes, it requires less room-shielding. The ability to switch the radiation source on and off reduces exposure of healthy tissues to unnecessary radiation. In this study, the Esteya ${ }^{\circledR}$ (Nucletron, an Elekta company, Elekta AB, Stockholm, Sweden) electronic brachytherapy system was used. It has an articulated arm specifically designed for surface procedures that adapts to flat lesion locations. The skin applicator is constructed with Tungsten shielding in such a way that radiation output is limited to the lesion of interest; radiation leakage to healthy tissues is virtually zero [3]. When compared to established HDR brachytherapy solutions with isotope based sources of radiation, a shorter treatment time is required in order to improve both the user and the patient experience [3]. Only a handful of studies have been reported to date $[4,5,6,7]$ suggesting EBT as an effective treatment with few recurrences or side effects and excellent cosmetic results. However, aforementioned studies are often retrospective and not peer reviewed before publishing. Higher level prospective research is needed on EBT for positioning this new technique [8] and confirming improved clinical outcome when compared to existing technologies. No studies to date have reported on optimizing fractionation schedules [9].

This study aims to investigate the outcomes of EBT using the Esteya ${ }^{\circledR}$ EBT system for the treatment of superficial and nodular basal cell carcinoma using two different radiation dose regimens in two groups of patients.

\section{Material and methods}

\section{Rationale for the study fractionation schedules}

The fractionation schedules used in this study aimed to deliver the same biological effective dose (BED) as in the treatment with the Valencia applicators (Nucletron, an Elekta company, Elekta AB, Stockholm, Sweden). As opposed to an EBT system, the latter are based on a ${ }^{192} \mathrm{Ir}$ radioactive source and a surface-specific applicator, which have been shown to provide excellent results in terms of control rate and cosmesis [10].

The BED estimates the true biological dose delivered by a combination of dose per fraction and total dose to a given tissue characterized by a specific $\alpha / \beta$ ratio. It is calculated by the equation BED $=$ nd $[1+\mathrm{d}(\alpha / \beta)]$, where $n$ is the number of fractions, $d$ is the dose/fraction, and $\alpha / \beta$ is a radiosensitivity coefficient [11]. Different histological classes of cancers have different $\alpha / \beta$ ratios and this can result in a different clinical response, despite the fact that the total dose has not changed. If the total dose is kept constant, the BED will increase if the dose per fraction is increased. In general, a value of $\alpha / \beta=10$ for the tumor is accepted $[12,13]$, although $\alpha / \beta=8.5$ has been suggested for skin cancers [14]. In a previous study with the Valencia applicators, the BED was 71.4 Gy when considering $\alpha / \beta=10$ and 78.8 Gy for $\alpha / \beta=8$ [15]. To achieve this 6 fractions of 7 Gy each prescribed at a given depth (usually 3 or $4 \mathrm{~mm}$ ), with 2 fractions per week with at least $48 \mathrm{~h}$ between consecutive fractions was used. In addition, the maximum skin dose (at $0 \mathrm{~mm}$ depth) per fraction was set to be lower than $10 \mathrm{~Gy}$ in order to avoid skin injuries [16].
In contrast to the Valencia applicators, Esteya ${ }^{\circledR}$ is an EBT system based on a $69.5 \mathrm{kVp}$ X-ray tube and a set of circular collimators that produce photon beams of $1 \mathrm{~cm}$ to $3 \mathrm{~cm}$ in diameter at a depth of $0 \mathrm{~mm}$. Thus, photons emitted in a treatment with Esteya ${ }^{\circledR}$ have considerably lower energy than photons emitted by a ${ }^{192} \mathrm{Ir}$ source. It has been reported that lower energy photons have a higher radiobiological effectiveness (RBE) [17]. This implies that a lower physical dose should be prescribed with EBT sources in order to achieve the same clinical results (i.e. the same BED) as with the higher energy brachytherapy sources (e.g. ${ }^{192}$ Ir Valencia applicators). The RBE depends on the photon spectrum and the dose per fraction applied. After a review of the literature $[18,19,20,21,22,23,24]$, it was estimated that the RBE for a $69.5 \mathrm{kVp}$ X-ray source, such as the one used by Esteya ${ }^{\circledR}$, is around 1.15. Based on this analysis, the same clinical results achieved with the Valencia applicators could be expected by prescribing 7 Gy/1.15 = 6.1 Gy per fraction, during 6 fractions, with 2 fractions per week. This was the fractionation schedule used with group 1 . Because the recurrence rates obtained in early results for this group were not as low as with the Valencia applicators, it was decided that the second group should be treated with the same fractionation as with the Valencia applicators (7 Gy per fraction), i.e., no $\mathrm{RBE}$ correction was applied in comparison to group 1.

In both groups, because the tolerance in dose homogeneity for the Esteya ${ }^{\circledR}$ beam is within $5 \%$, a $9.5 \mathrm{~Gy}$, threshold dose was established in order to be sure that the maximum skin dose per fraction was lower than $10 \mathrm{~Gy}$. The dose gradient for the Esteya ${ }^{\circledR}$ source is lower than that for the Valencia applicators [25], which results in an even lower dose at the surface, and therefore this maximum skin dose per fraction was never reached either using 7 Gy or 6.1 Gy per fraction.

\section{Study design}

Two prospective, single-center, non-randomized, pilot studies to assess the outcome of electronic brachytherapy in superficial and nodular basal cell carcinoma treatment using Esteya ${ }^{\circledR}$ surface applicators were conducted sequentially.

Two groups of 20 patients were treated sequentially with different doses. The second group studied received a differently calculated dose because similar results to the Valencia applicator studies were not achieved with the dose used in the first group.

The first group (1) included 20 patients with 20 lesions treated with $36.6 \mathrm{~Gy}$ in 6 fractions of $6.1 \mathrm{~Gy}$, two times a week during three weeks, with at least 2 days between each consecutive fraction. The second group (2) included 20 patients with 20 lesions treated with 42 Gy in 6 fractions of 7 Gy, two times a week during three weeks, with at least 2 days between each consecutive fraction. Thus, all fractionation and overall times were kept the same with the exception of the dose per fraction. In one arm, the $6.1 \mathrm{~Gy} /$ fraction resulting from the theoretical RBE calculation was used, and in the second arm (7 Gy/fraction), the same dose as in the Valencia applicator study was used. 
The study was conducted from May 2014 to July 2015. It was approved by the Ethics Committee of Clinical Research of the La Fe Hospital.

\section{Eligibility}

Only adults with a primary superficial or nodular BCC with T1 and T2 clinical stage according to AJCC 2010 criteria [26] were included. T1 includes tumors $\leq 2 \mathrm{~cm}$ with less than 2 high risk features, and T2 includes tumors $>2 \mathrm{~cm}$ or any tumor with 2 or more high risk features. These high risk features are: $>2 \mathrm{~mm}$ thickness, Clark level $\geq 4$, perineural invasion, tumor located on the ear or hair-bearing lip, and undifferentiated or poorly differentiated tumors. Other forms of BCC or clinical stage more than T2 were excluded. Due to applicator design, lesions bigger than $20 \mathrm{~mm}$, deeper than $4 \mathrm{~mm}$, or located on irregular surfaces were also excluded [15]. All patients or legal guardians signed a written informed consent.

\section{Procedure, monitoring, and follow up}

All BCC's were confirmed by histopathologic examination. Tumor depth was assessed by high frequency ultrasonography (HFUS) and a $3 \mathrm{~mm}$ punch-biopsy taken from the clinically most representative area in terms of depth [27]. Lateral margin delimitation was assessed clinically and aided by a dermoscope [28]. A lateral margin of $5 \mathrm{~mm}$ was added to establish the treatment area [15].
All patients were followed for at least 1 year. Patients were seen after treatment at 2 weeks, 6 weeks, 3 months, 6 months, and 1 year. Complete and partial response were defined by the absence or the presence of residual tumor clinically and aided by dermoscopy at each follow-up visit. When there was any doubt about tumor persistence or recurrence, a biopsy was performed for confirmation by histopathology. Biopsies were always taken at or after the 3 months check-up. CTCAE v4.0 (Common Terminology Criteria for Adverse Events) toxicity scales [29] were used to assess acute toxicity and RTOG-EORTC scales [30] related to brachytherapy were used to assess cosmesis.

\section{Statistics}

Mean \pm standard deviation was reported for continuous data and percentage \pm standard deviation for categorical data. To compare categorical data, we utilized a nonparametric test (Kendall Tau B) due to the presence of a percentage of $<5 \%$ in one group. Statistical analysis was performed with the SPSS Statistics $18^{\circledR}$ (SPSS Inc, Chicago, USA) program. We considered $p$ values of $<0.05$ to be significant.

\section{Results}

The baseline characteristics of the two populations are shown in Table 1. Patients treated with 36.6 Gy are shown

Table 1. Baseline patients characteristics

\begin{tabular}{|c|c|c|c|}
\hline & Group 1 & Group 2 & $p$ \\
\hline Women, $n(\%)$ & $10(50)$ & $8(40)$ & ns \\
\hline Age, years & $70 \pm 3$ & $79 \pm 2$ & 0.006 \\
\hline \multicolumn{4}{|l|}{ Skin phototype, $n$ (\%) } \\
\hline 2 & $9(45)$ & $10(50)$ & ns \\
\hline 3 & $11(55)$ & $10(50)$ & \\
\hline Antithrombotic therapy, $n$ (\%) & $6(30)$ & $6(30)$ & ns \\
\hline \multicolumn{4}{|l|}{ Tumor location, $n$ (\%) } \\
\hline Head and neck & $15(75)$ & $15(75)$ & ns \\
\hline Trunk and extremities & $5(25)$ & $5(25)$ & \\
\hline \multicolumn{4}{|l|}{ BCC type, $n(\%)$} \\
\hline Superficial & $10(50)$ & $8(40)$ & ns \\
\hline Nodular & $10(50)$ & $12(60)$ & \\
\hline Pigmented BCC, $n$ (\%) & $9(45)$ & $7(35)$ & ns \\
\hline Ulcerated BCC, $n$ (\%) & $5(25)$ & $1(5)$ & ns \\
\hline Breslow (mm) & $1.43 \pm 0.21$ & $1.58 \pm 0.18$ & ns \\
\hline Tumor diameter (mm) & $11.54 \pm 0.96$ & $12.2 \pm 0.68$ & ns \\
\hline \multicolumn{4}{|l|}{ Dose depth, $n$ (\%) } \\
\hline $3 \mathrm{~mm}$ & $18(90)$ & $17(85)$ & ns \\
\hline $4 \mathrm{~mm}$ & $2(10)$ & $3(15)$ & \\
\hline
\end{tabular}

Group 1-20 patients treated at 36.6 Gy delivered in 6 fractions; Group 2-20 patients treated at 42 Gy delivered in 6 fractions; ns - non-significant (>0.05) 


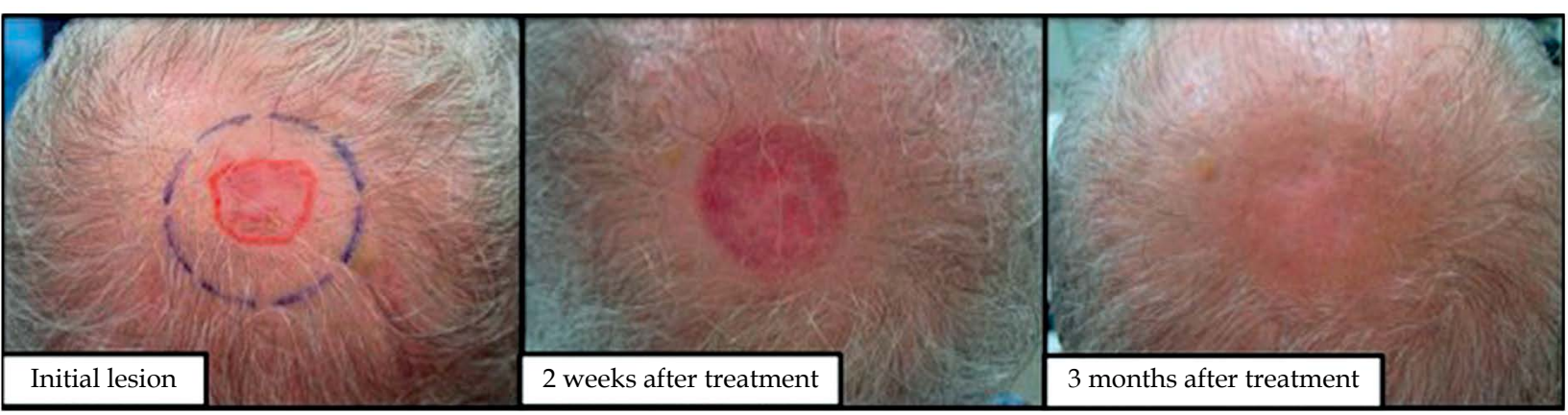

Fig. 1. Example of complete response

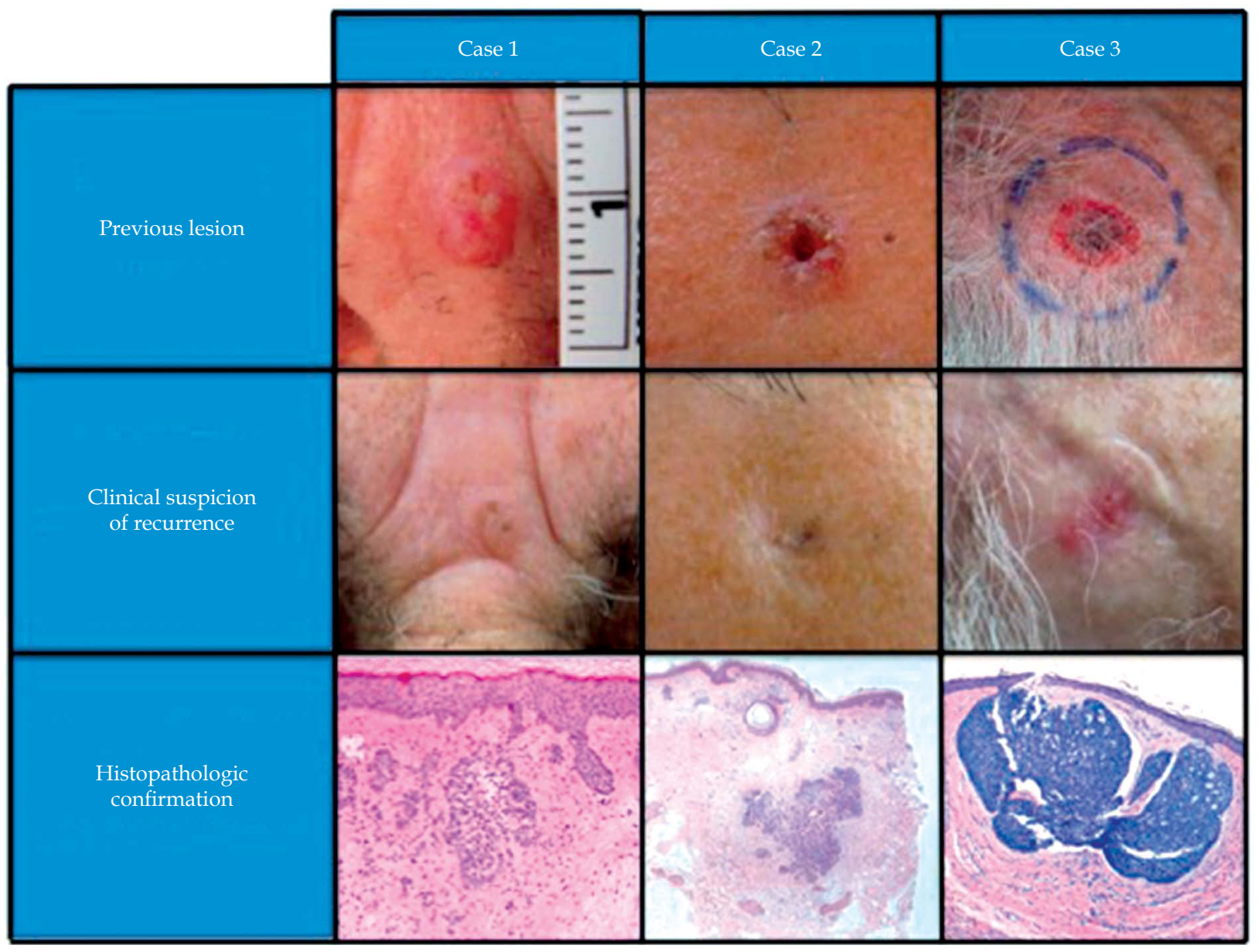

Fig. 2. Clinical and histopathological pictures of recurrent cases

in the left column (group 1) and patients treated with $42 \mathrm{~Gy}$ are shown in the right column (group 2). Both groups were comparable in all collected baseline characteristics except age $(p=0.006)$.

In group 1, a complete response in $90 \%$ of cases was observed, whereas in group 2 the complete response was 95\% (Figure 1). This difference was not statistically significant probably due to the small sample size.

Tumor persistence or recurrence was suspected clinically and dermoscopically in two patients in the first group at 3 and 6 months, respectively, and in one patient in the second group at 1 year follow-up. This was confirmed by histopathology after resection of the remaining tumor, which was a diagnostic as well as a curative procedure (Figure 2).

Acute toxicity in the first group was G1 in 65\% of cases due to erythema and G2 in 35\% due to ulceration (Figure 3). In the second group, $60 \%$ of patients presented with G1 toxicity and 40\% with G2. The cosmetic result was G0 (no cutaneous alterations) in $61 \%$ of patients in the first group and $55 \%$ in the second group. The rest of the patients only showed pigmentation alterations or alopecia, corresponding to a G1 cosmetic result (Figure 3). These differences in acute toxicity and cosmetic results between the two treatment groups were not statistically significant $(p>0.05)$. Results are shown in Table 2 . 


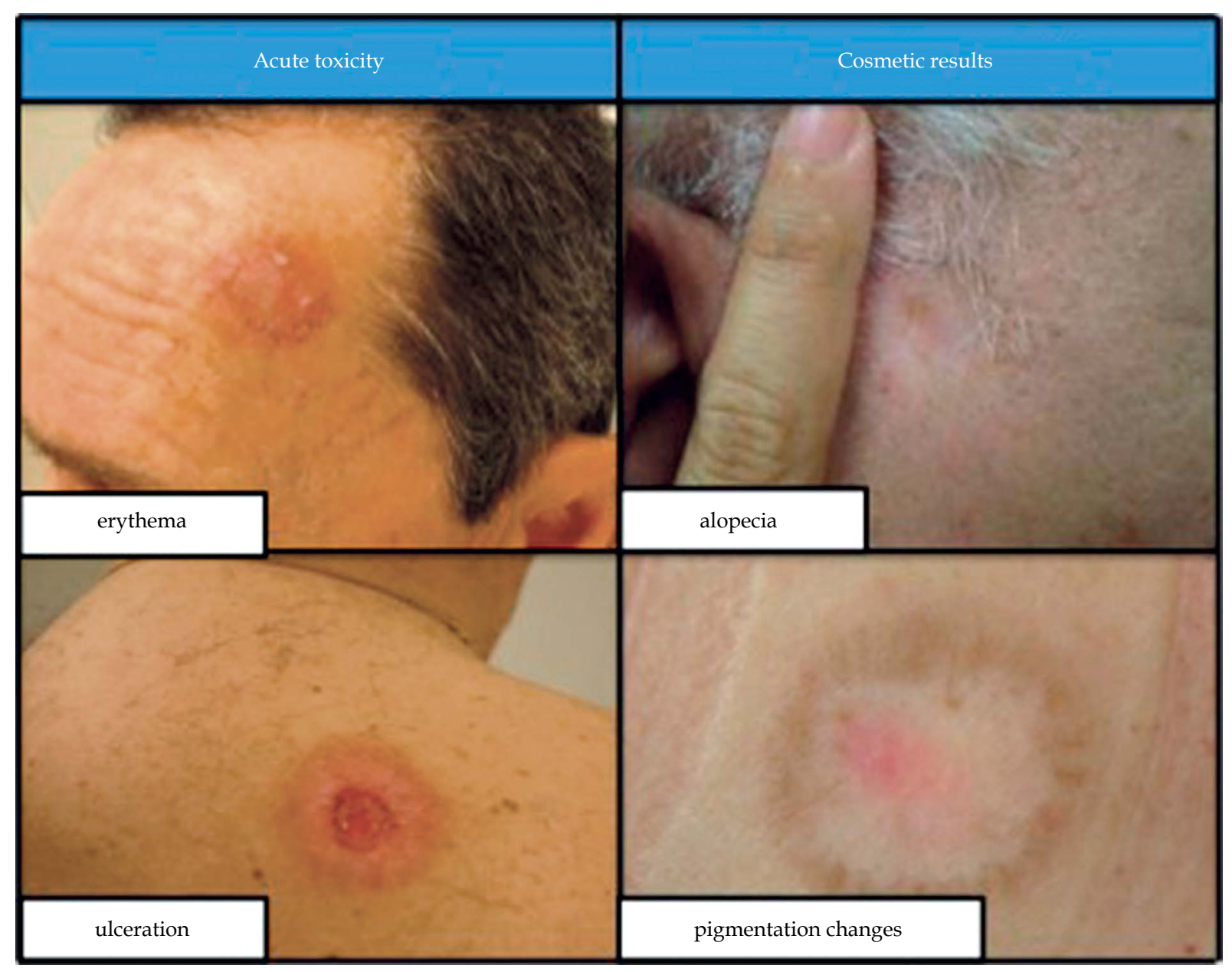

Fig. 3. Examples of acute toxicity and cosmetic result

Table 2. Results

\begin{tabular}{|c|c|c|c|}
\hline & Group 1 & Group 2 & $p$ \\
\hline \multicolumn{4}{|l|}{ Acute toxicity (\%) } \\
\hline G1 (erythema) & 65 & 60 & \multirow{2}{*}{ ns } \\
\hline G2 (ulceration) & 35 & 40 & \\
\hline \multicolumn{4}{|l|}{ Cosmetic result (\%) } \\
\hline G0 (no skin alteration) & 61 & 55 & \multirow{2}{*}{ ns } \\
\hline G1 (pigmentation changes or alopecia) & 39 & 45 & \\
\hline \multicolumn{4}{|l|}{ Response } \\
\hline Complete & 90 & 95 & \multirow{2}{*}{ ns } \\
\hline Partial & 10 & 5 & \\
\hline \multicolumn{4}{|l|}{ Recurrences } \\
\hline Number (\%) & $2(10)$ & $1(5)$ & \\
\hline Location & Forehead (both) & Right temple & \\
\hline Tumor diameter (mm) & 8 and 5 & 12 & \\
\hline Depth $(\mathrm{mm})$ & 2.7 and 3.1 & 2.2 & \\
\hline Applicator used (mm) & 20 and15 & 25 & \\
\hline Dose depth (mm) & 3 and 4 & 3 & \\
\hline Time to recurrence (months) & 3 and 6 & 12 & \\
\hline Second-line treatment & Resection & Resection & \\
\hline
\end{tabular}

Group 1-20 patients treated at 36.6 Gy delivered in 6 fractions; Group 2-20 patients treated at 42 Gy delivered in 6 fractions; ns - non-significant (>0.05) 
Table 3. Comparison between different protocols of HDR-BT and EBT for BCC

\begin{tabular}{|c|c|c|c|c|c|c|c|c|c|c|}
\hline Author & $\begin{array}{l}\text { Number of } \\
\text { NMSC/BCC }\end{array}$ & Applicator & $\begin{array}{c}\text { No. of } \\
\text { fractions }\end{array}$ & $\begin{array}{l}\text { Total } \\
\text { dose } \\
(\mathrm{Gy})\end{array}$ & $\begin{array}{c}\text { Dose/ } \\
\text { fraction } \\
(G y)\end{array}$ & Frequency & Prescription & $\begin{array}{l}\text { BED } \\
\text { keV }\end{array}$ & $\begin{array}{l}\text { Median } \\
\text { followup } \\
\text { (months) }\end{array}$ & $\begin{array}{c}\text { Local } \\
\text { control } \\
(\%) \\
\end{array}$ \\
\hline $\begin{array}{l}\text { Köhler-Brock } \\
\text { et al. [40] }\end{array}$ & $520 / 282$ & Leipzig & - & $30-40$ & $5-10$ & $\begin{array}{l}\text { 1-2 times } \\
\text { a week }\end{array}$ & $6-8 \mathrm{~mm}$ & - & $6-125$ & 91 \\
\hline Gauden et al. [37] & $92 /$ & Leipzig & 12 & 36 & 3 & Daily & $\begin{array}{l}\text { Leipzig } \\
\text { appropiate } \\
\text { depth }\end{array}$ & 46.8 & 37 & 97 \\
\hline Ghaly et al. [36] & $67 /$ & Leipzig & 8 & 40 & 5 & $\begin{array}{l}\text { Twice } \\
\text { a week }\end{array}$ & $\begin{array}{l}\text { Leipzig } \\
\text { appropiate } \\
\text { depth }\end{array}$ & 60.0 & 18 & 95.5 \\
\hline Tormo et al. [10] & $48 / 45$ & Valencia & 6 & 42 & 7 & $\begin{array}{l}\text { Twice } \\
\text { a week }\end{array}$ & $4 \mathrm{~mm}$ & 70.0 & - & 98 \\
\hline Delishaj et al. [33] & $53 / 42$ & Valencia & $8-10$ & $40-50$ & 5 & $\begin{array}{l}\text { 2-3 times } \\
\text { a week }\end{array}$ & - & $\begin{array}{l}60.0- \\
75.0\end{array}$ & 12 & 96.2 \\
\hline Bhatnagar $[4,35]$ & $297 / 167$ & EBT $\left(\mathrm{Xoft}^{\oplus}\right)$ & 8 & 40 & 5 & $\begin{array}{l}\text { Twice } \\
\text { a week }\end{array}$ & $\begin{array}{c}\text { Depth base } \\
\text { don } \mathrm{CT} \\
\text { or } 3 \mathrm{~mm}\end{array}$ & 50 & 16.5 & 99 \\
\hline Dogget et al. [5] & $565 / 238$ & EBT $\left(\mathrm{Xoft}^{\oplus}\right)$ & 8 & 40 & 5 & $\begin{array}{l}\text { Twice } \\
\text { a week }\end{array}$ & - & 50.0 & 12.5 & 99.8 \\
\hline Strimling et al. [6] & $508 / 275$ & EBT $\left(\mathrm{Xoft}^{\oplus}\right)$ & 8 & 40 & 5 & $\begin{array}{l}\text { Twice } \\
\text { a week }\end{array}$ & $0-5 \mathrm{~mm}$ & - & 3.4 & 99.4 \\
\hline Paravati et al. [7] & $154 / 149$ & EBT $\left(\mathrm{Xoft}^{\oplus}\right)$ & 8 & 40 & 5 & $\begin{array}{c}\text { Twice } \\
\text { a week }\end{array}$ & $2-3 \mathrm{~mm}$ & - & 16 & 98.7 \\
\hline Ballester et al. [27] & $40 / 40$ & $\begin{array}{c}\text { EBT } \\
\left(\text { Esteya }^{\circledR}\right)\end{array}$ & 6 & $36.6-42$ & $6.1-7$ & $\begin{array}{l}\text { Twice } \\
\text { a week }\end{array}$ & $\begin{array}{l}\text { Esteya }^{\oplus} \\
\text { applicators }\end{array}$ & 69.5 & 12 & $90-95$ \\
\hline
\end{tabular}

BCC-basal cell carcinoma; BED - biological effective dose, NMSC - non melanoma skin cancer; EBT-electronic brachytherapy; HDR-BT-high-dose-rate brachytherapy

\section{Discussion}

When treating $\mathrm{BCC}$, dermatologists have a wide range of possibilities but surgery and RT are the treatments with the lowest recurrence rates [31]. Surgery is often the first choice of treatment due to its high efficacy and because it is a straightforward procedure. Despite the high incidence of BCC, however, there is only one randomized study comparing surgery to RT, which was published in the late nineties [32]. In this study, only primary facial BCC less than $4 \mathrm{~cm}$ were included. Three hundred and forty-seven patients were treated, 174 with surgery and 173 with RT followed up over 4 years. It was concluded that surgery has a lower failure rate and better cosmesis than RT. Although this was a randomized study, it has several weaknesses. Firstly, the radiotherapy group was not homogeneous since patients were treated with interstitial brachytherapy, contact therapy, or conventional radiotherapy. Further, doses and fractionation in each RT type were not the same. Secondly, the use of flaps and grafts to close the wounds in the surgery group may have made the detection of persistence or recurrence more difficult. Thirdly, additional resection was performed in $39 \%$ of patients from the surgery group. Finally, only facial tumors were included, therefore we have no data about other locations.

Radiotherapy has been a part of the dermatologist's treatment armamentarium for several decades but, since the eighties, this has been changing in favor of dermato- logic surgery. This is basically due to the incorporation of surgery in dermatology and the difficulties of administering radiation in unshielded offices. In addition, in many countries dermatologists are not allowed anymore to administer RT themselves, thus they have to send patients to another department or clinic if they opt for RT. Consequently, surgery has experienced a great surge in development in recent years in dermatology departments and offices, whereas RT has reduced noticeably in significance, being used only in cases when surgery is contraindicated.

Electronic brachytherapy has appeared as an alternative to more conventional RT techniques such as electron beam or high-dose-rate radionuclide-based brachytherapy. Electron beams require a bolus and a more specific dosimetry, which makes it more complex in clinical practice. On the other hand, radionuclide-based brachytherapy uses a radioactive source, generally ${ }^{192} \mathrm{Ir}$, which emits photons of higher energy than EBT sources. This results in EBT requiring less room shielding, and being safer, simpler and easier to apply. In radionuclide-based brachytherapy some applicators exist, which shield the radiation emitted by the ${ }^{192}$ Ir source except for the region that needs to be irradiated. Among them, the Valencia applicators [10] were designed specifically to produce a collimated and homogeneous dose distribution within the patient's skin [33]. Compared to these applicators, EBT has the advantage of a shorter treatment time (2.5 minutes compared to 5 to 10 minutes), lower penumbra (i.e. 
sharper lateral dose fall-off) [23], less radiation leakage that implies lower peripheral dose, and a broader range of applicator sizes, resulting in a more conformal treatment. For these reasons, EBT is a promising technique for the treatment of skin lesions.

So far, to the best of our knowledge, only four studies have been performed using EBT for BCC (despite the fact that these authors treat other NMSC also). These four groups used the Xoft Axxent ${ }^{\circledR}$ Electronic $\left(\mathrm{eBx}^{\circledR}\right)$ Brachytherapy System ${ }^{\circledR}$ (Xoft Inc., San Jose, CA, USA). Bhatnagar et al. reported 147 cases of BCC [4], Dogget et al. 238 cases [5], Strimling et al. 275 [6], and Paravati et al. 149 [7]. These studies showed clinical cure rates higher than $98 \%$ with acceptable acute toxicities and very good cosmesis. All of them used a dose of $40 \mathrm{~Gy}$ in 8 equal fractions, 5 Gy per fraction, delivered twice weekly with at least 48 hours between each fraction. Long-term follow-up has not yet been achieved because most patients have not reached their second year of follow-up.

In our experience with the Esteya ${ }^{\circledR}$ system, the better dose to achieve the highest clinical cure rate is $42 \mathrm{~Gy}$ in 6 equal fractions, i.e. 7 Gy per fraction given at the prescription depth (typically $3 \mathrm{~mm}$ ) [34]. This is delivered twice weekly with a minimum interval of 48 hours. Tormo et al. [10] also showed good toxicity results in patients treated in 6 or 7 fractions. Although most brachytherapy treatment schemas in the literature use 8 to 12 fractions $[35,36,37,38,39,40]$, the fractionation used in this study does not result in a higher toxicity or a poorer cosmesis in comparison with a more fractionated treatment. Thus, in an elderly population, a comfortable schema that facilitates compliance is preferred. For these reasons, a 6 fractions schema was chosen. In order to reduce the number of fractions to 5 , while keeping at the same time the same biological effective dose (BED), 8 Gy per fraction at the prescription depth (typically $3 \mathrm{~mm}$ ) would be required. However, the latter would result in a skin dose (i.e. at $0 \mathrm{~mm}$ depth) of $9.9 \mathrm{~Gy}$ per fraction, which, taking into account a 5\% tolerance in dose homogeneity, would fail to guarantee compliance with the FDA recommendations [16] regarding the maximum skin dose to avoid toxicity.

Despite the solid radiobiological basis, three cases showed tumor persistence or recurrence. In group 1, treated at $36.6 \mathrm{~Gy}$, this occurred early, one case at 3 and one at 6 months. Both were persistent cases because the lesion was decreasing in size but never disappeared. The only failed case in group 2, treated at $42 \mathrm{~Gy}$, occurred late, at 1 year follow-up. In this case, the lesion initially disappeared clinically but later reappeared. These cases were analyzed separately with regard to high frequency ultrasonography, previous biopsy, and histopathology from the persistent or recurrent tumor. Medical records, clinical, and dermoscopic features of all visits were reviewed. Despite this, we did not find any reason that could justify the failure of the treatment.

We do realize that this study has several limitations. The small sample size and the short-term follow-up being the main ones. We included a limited number of patients because this was a pilot study. The follow-up performed is probably insufficient to assess efficacy but these early results could be a trend in terms of clinical results. All patients will have further follow-up in order to assess longterm response and to rule out recurrences.

As more studies are performed, we learn more about the biology and behavior of different cutaneous tumors. There are many patients with BCC and at the same time there are new treatments becoming available. All of this allows us to individualize treatment depending on patient and tumor characteristics. In the near future, EBT will probably be one more treatment option available for patients with BCC. Dermatologists should know about this new technique in order to add it to their current treatment strategies.

\section{Conclusions}

Our initial experience with the Esteya ${ }^{\circledR}$ EB system to treat superficial and nodular BCC shows that a dose of $36.6 \mathrm{~Gy}$ and $42 \mathrm{~Gy}$ delivered in 6 fractions of $7 \mathrm{~Gy}$ achieves a $90 \%$ and $95 \%$ clinical cure rate at 1 year, respectively. Both groups had a tolerable toxicity and a very good cosmesis.

Further investigation with respect to EBT for treating skin tumors is needed, ideally high-level evidence in the form of randomized clinical trials, to compare results with modern treatment protocols with those obtained with surgery. Surgery remains the treatment of choice today, and EBT's role and position is yet to be defined. It will probably become an established option for selected patients in the near future.

\section{Disclosure}

This study was supported by Nucletron (Nucletron, an Elekta company, Elekta AB, Stockholm, Sweden), by Generalitat Valenciana (Project PROMETEOII/2013/010) and by Spanish Government under Project No. FIS201342156.

Authors report no conflict of interest.

\section{References}

1. Lear W, Dahlke E, Murray CA. Basal cell carcinoma: review of epidemiology, pathogenesis, and associated risk factors. J Cutan Med Surg 2007; 11: 19-30.

2. Roozeboom MH, Arits AH, Nelemans PJ et al. Overall treatments success after treatment of primary superficial basal cell carcinoma: A systematic review and meta-analysis of randomized and nonrandomized trials. Br J Dermatol 2012; 167: 733-756.

3. Candela-Juan C, Niatsetski Y, Ouhib Z et al. Commissioning and periodic tests of the Esteya ${ }^{\circledR}$ electronic brachytherapy system. J Contemp Brachytherapy 2015; 7: 189-195.

4. Bhatnagar A. Electronic brachytherapy for the treatment of non-melanoma skin cancer: results up to 5 years. Proceedings of the $73^{\text {th }}$ annual meeting of the American Academy of Dermatology; 2015 March 20-24; San Francisco, USA.

5. Dogget S, Willoughby M, Mafong E et al. Electronic brachytherapy for non-melanoma skin cancer: report of first 565 lesions. Proceedings of the $73^{\text {th }}$ annual meeting of the American Academy of Dermatology; 2015 March 20-24; San Francisco, USA.

6. Strimling RB, Jones CL, Schaeffer J et al. Initial experience of electronic brachytherapy for the treatment of 494 non-mela- 
noma skin cancer (NMSC) lesions in 297 patients. Proceedings of the $73^{\text {th }}$ annual meeting of the American Academy of Dermatology; 2015 march 20-24; San Francisco, USA.

7. Paravati AJ, Hawkins PG, Martin AN et al. Clinical and cosmetic outcomes in patients treated with high-dose-rate electronic brachytherapy for nonmelanoma skin cancer. Pract Radiat Oncol 2015; 5: 659-664.

8. Linos E, Van Beek M, Resneck JS. A sudden and concerning increase in the use of electronic brachytherapy for skin cancer. JAMA Dermatol 2015; 151: 699-700.

9. Ouhib Z, Kasper M, Perez Calatayud J et al. Aspects of dosimetry and clinical practice of skin brachytherapy: The American Brachytherapy Society working group report. Brachytherapy 2015; 14: 840-858.

10. Tormo A, Celada F, Rodriguez S et al. Non-melanoma skin cancer treated with HDR Valencia applicator: clinical outcomes. J Contemp Brachytherapy 2014; 6: 167-172.

11. Jones B, Dale RG, Deehan C et al. The role of biologically effective dose (BED) in clinical oncology. Clin Oncol ( $R$ Coll Radiol) 2001; 13: 71-81.

12. Onishi H, Araki T, Shirato H et al. Stereotactic hypofractionated high-dose irradiation for stage I non-small cell lung carcinoma: clinical outcomes in 245 subjects in a Japanese multiinstitutional study. Cancer 2004; 101: 1623-1631.

13. Pötter R, Haie-Meder C, van Limbergen E et al. Recommendations from gynaecological (GYN) GEC ESTRO working group (II): concepts and terms in 3D image-based treatment planning in cervix cancer brachytherapy - 3D dose volume parameters and aspects of 3D image-based anatomy, radiation physics, and radiobiology. Radiother Oncol 2006; 78: 67-77.

14. Trott KR, Maciejewski B, Preuss-Bayer G et al. Dose-response curve and split-dose recovery in human skin cancer. Radiother Oncol 1984; 2: 123-129.

15. Pons-Llanas O, Ballester-Sánchez R, Celada-Álvarez FJ et al. Clinical implementation of a new electronic brachytherapy system for skin brachytherapy. J Contemp Brachytherapy 2014; 6: 417-423.

16. Food and Drug Administration (FDA). Avoidance of serious x-ray-induced skin injuries to patients during fluoroscopically-guided procedures. Fed Regist 1994; 59: 26402-26405.

17. Reniers B, Liu D, Rusch T et al. Calculation of relative effectiveness of a low-energy electronic brachytherapy source. Phys Med Biol 2008; 53: 7125-7135.

18. Bistrović M, Bišćan M, Viculin T. RBE of $20 \mathrm{kV}$ and $70 \mathrm{kV}$ X-rays determined for survival of V 79 cells. Radiother Oncol 1986; 7: 175-180

19. Brenner DJ, Leu CS, Beatty JF et al. Clinical relative biological effectiveness of low-energy x-rays emitted by miniature x-ray devices. Phys Med Biol 1999; 44: 323-333.

20. Verhaegen F, Reniers B. Microdosimetric analysis of various mammography spectra: lineal energy distributions and ionization cluster analysis. Radiat Res 2004; 162: 592-599.

21. Kühne M, Urban G, Frankenberg D et al. DNA double-strand break misrejoining after exposure of primary human fibroblasts to $\mathrm{CK}$ characteristic $\mathrm{X}$ rays, $29 \mathrm{kVp}$ X rays and ${ }^{60} \mathrm{Co}$ gamma rays. Radiat Res 2005; 164: 669-676.

22. Mestres M, Caballín MR, Barrios L et al. RBE of $X$ rays of different energies: a cytogenetic evaluation by FISH. Radiat Res 2008; 170: 93-100.

23. Bernal MA, de Almeida CE, David M et al. Estimation of the RBE of mammography-quality beams using a combination of a Monte Carlo code with a B-DNA geometrical model. Phys Med Biol 2011; 56: 7393-7403.

24. Flickinger JC. A radiobiological analysis of multicenter data for postoperative keloid radiotherapy. Int J Radiat Oncol Biol Phys 2011; 79: 1164-1170.
25. García-Martínez T, Chan JP, Perez-Calatayud J et al. Dosimetric characteristics of a new unit for electronic skin brachytherapy. J Contemp Brachytherapy 2014; 6: 45-53.

26. Edge SB, Compton CC. The American Joint Committee on Cancer: the 7th edition of the AJCC cancer staging manual and the future of TNM. Ann Surg Oncol 2010; 17: 1471-1474.

27. Ballester-Sánchez R, Pons-Llanas O, Llavador-Ros $\mathrm{M}$ et al. Depth determination of skin cancers treated with superficial brachytherapy: ultrasound vs histopathology. J Contemp Brachytherapy 2014; 6: 356-361.

28. Ballester-Sánchez R, Pons-Llanas O, Pérez-Calatayud J et al. Dermoscopy margin delineation in radiotherapy planning for superficial or nodular basal cell carcinoma. $\mathrm{Br} J$ Dermatol 2014; 172: 1162-1163.

29. CTCAE v4.0: NIH Publication No. 09-5410.

30. Cox JD, Stetz J, Pajak TF. Toxicity criteria of the Radiation Therapy Oncology Group (RTOG) and the European Organization for Research and Treatment of Cancer (EORTC). Int J Radiat Oncol Biol Phys 1995; 31: 1341-1346.

31. Bath-Hextall FJ, Perkins W, Bong J et al. Interventions for basal cell carcinoma of the skin. Cochrane Database Syst Rev 2007; 24: CD003412.

32. Avril MF, Auperin A, Margulis A et al. Basal cell carcinoma of the face: surgery or radiotherapy? Results of a randomized study. Br J Cancer 1997; 76: 100-106.

33. Delishaj D, Manfredi B, Laliscia C et al. Non-melanoma skin cancer treated with HDR Brachytherapy and Valencia applicator in elderly patients. Eur J Cancer 2015; 51: S669.

34. Ballester-Sánchez R, Pons-Llanas O, Candela-Juan C et al. Efficacy and safety of electronic brachytherapy for superficial and nodular basal cell carcinoma. J Contemp Brachytherapy 2015; 7: 231-238.

35. Bhatnagar A. Nonmelanoma skin cancer treated with electronic brachytherapy: results at 1 year. Brachytherapy 2013; 12 : 134-140.

36. Ghaly M, Zinkin H, Dannenberg $M$ et al. HDR brachytherapy with standardized surface applicators in the treatment of superficial malignant skin lesions. Int J Radiat Oncol Biol Phys 2008; 72: 505-506.

37. Gauden S, Egan C, Pracy M. HDR brachytherapy for the treatment of the skin cancer using standard surface applicators. Brachytherapy 2008; 7: S159.

38. Amendola BE, Amendola MA, Fowler J. Dermatological applications of HDR using surface applicators using a shorter treatment schedule. Brachytherapy 2006; 5: S106.

39. Fabrini MG, Perrone F, De Liguoro $M$ et al. High dose rate brachytherapy in a large squamous cell carcinoma of the hand. Brachytherapy 2008; 7: 270-275.

40. Kohler-Brock A, Prager W, Pohlmann S et al. The indications for and results of HDR afterloading therapy in diseases of the skin and mucosa with standardized surface applicators (the Leipzig Applicator). Strahlenther Onkol 1999; 175: 170-174. 